\title{
ANALISIS GEOMETRI PELURU TERHADAP NILAI DRAG COEFFICIENT PADA KECEPATAN 304,8 m/s
}

\author{
I Wayan Sugita, Muhamad Al Afif Dzaky \\ Jurusan Teknik Mesin, Fakultas Teknik, Universitas Negeri Jakarta \\ e-mail : wayan-sugita@unj.ac.id
}

\begin{abstract}
ABSTRAK
Tujuan dari penelitian ini adalah untuk mengetahui nilai drag coefficient dari peluru senapan angin dengan menggunakan software Ansys Fluent 15.0 dan untuk mengetahui pengaruh distribusi tekanan, kecepatan, dan pathline velocity terhadap nilai drag coefficient. Penelitian dilakukan dengan menggunakan peluru senapan angin dengan bentuk kepala field point, flat nosed dan round head dengan variasi bentuk badan skirt dan lurus.

Hasil penelitian menunjukkan bahwa disetiap bentuk kepala pelara peluru dan variasi badannya mengalami kecepatan dan tekanan yang berbeda dan menghasilkan gaya yang berbeda, drag coefficient yang terbesar dialami oleh bentuk kepala peluru flat nosed dan yang terendah dialami oleh bentuk kepala peluru round head dapat diketahui bawah, dengan bentuk kepala yang lebih luas menghasilkan tekanan udara yang besar pada ujung kepala peluru, perbedaan tekanan pada bagian depan dan belakang peluru yang besar menghasilkan nilai drag coefficient yang besar.Hasil dari simulasi mendapatkan nilai drag coefficient pada peluru filed point skirt sebesar 0,5219 field point lurus sebesar 0,5045 flat nosed skirt sebesar 0,5943 flat nosed lurus sebesar 0,5773 round head skirt sebesar 0,4313 round head lurus sebesar 0,4232 dengan kecepatan angin sebesar $304,8 \mathrm{~m} / \mathrm{s}$.
\end{abstract}

Kata Kunci: Computational Fluid Dynamic, Drag Coefficient, Peluru Senapan Angin

\section{PENDAHULUAN}

Peluru senapan angin memiliki beberapa jenis yang dibedakan dari bentuk kepala peluru. Dalam aplikasinya tidak hanya satu macam bentuk kepala peluru yang dilewati oleh aliran fluida, tapi terdapat banyak macam bentuk kepala peluru yang direkayasa sehingga sesusai dengan fungsi yang diinginkan. Bentuk kepala peluru yang berbeda akan menghasilkan karakteristik aliran fluida yang berbeda dan sangat berpengaruh terhadap fungsi dari bentuk kepala peluru tersebut.

Aliran fluida yang melingkupi sebuah benda secara penuh akan menimbulkan tegangan pada benda tersebut, baik tegangan normal maupun tegangan geser. Tegangan normal disebabkan karena adanya tekanan dari fluida, sedangkan tegangan geser timbul akibat adanya viskositas fluida. Jika kita tinjau pada aliran dua dimensi, aliran yang mengalir secara horizontal akan menimbulkan gaya drag atau gaya hambat karena arah dari gaya ini berlawanan dengan arah aliran. Gaya drag sering dianggap mengganggu, tetapi dalam situasi tertentu gaya drag justru diharapkan.

Untuk dapat mereduksi dan mengeliminasi implikasi tersebut, maka diperlukan modifikasi geometri. Dengan memodifikasi atau mendesain ulang geometri diharapkan mampu menghasilkan drag coefficient yang semakin kecil sehingga hambatan udara menjadi kecil dan aliran fluida dapan dengan lancar melewati benda tersebut. Belum banyak penelitian yang dilakukan untuk mendapatkan desain optimal. Sampai saat ini para peneliti belum mampu menemukan solusi yang tepat untuk mendiagnosa dan mensitesa gaya hambat udara, sehingga dilakukan pengujian langsung melalui eksperimen. Untuk validasi hasil-hasil eksperimen disertakan kajian computational fluid dynamics. Dengan model turbulen dan propertis yang tepat, diharapkan studi CFD dapat memprediksi pola aliran dengan tepat sesuai hasil eksperimen. Dengan dilakukan penelitian diharapkan dapat ditentukan nilai drag coefficient dari model peluru senapan angina 
dan pengaruh bentuk geometri kepala peluru dengan terhadap drag coefficient.

\section{Landasan Teori}

Dalam Aerodinamika dikenal beberapa gaya yang bekerja pada sebuah benda dan lebih spesifik lagi pada mobil seperti dikemukakan oleh Djoeli Satrijo (Djoeli,1999:53). Tahanan Aerodinamika, gaya angkat aerodinamik, dan momen angguk aerodinamik memiliki pengaruh yang bermakna pada unjuk kendaraan pada kecepatan sedang dan tinggi.

\subsection{Geometri Benda}

Geometri benda dapat dibagi dalam tiga kelompok utama, yaitu dua dimensi, tiga dimensi, dan axisymetric. Benda dua dimensi menurut Gerhart (Gerhart,1985:510) adalah benda yang memiliki bentuk sama pada seluruh bidang yang tegak lurus dengan sumbunya dimana sumbu benda memiliki panjang tak berhingga. Dengan kata lain bentuk benda sama pada seluruh bidang yang sejajar dengan kertas. Benda tiga dimensi memiliki panjang yang terbatas. Benda ini bisa memiliki bentuk yang sama dalam bidang tegak lurus dengan sumbu panjangnya, ataupun tidak. Benda axisymmetric adalah benda putar dengan bagian melintangnya berbentuk lingkaran. Benda ini memiliki bentuk yang sama pada seluruh bidang meridional $(x, r)$.

\subsection{Aliran Fluida}

Aliran laminar adalah aliran fluida yang bergerak dengan kecepatan yang sama dan dengan lintasan partikel yang tidak memotong atau menyilang, dapat dikatakan bahwa aliran laminar ditandai dengan keteraturan aliran fluida dengan Reynold Number di bawah $10^{5}$. Aliran turbulen adalah gerakan fluida yang tidak lagi tenang melainkan menjadi bergolak. Pada aliran turbulen partikel fluida tidak membuat fluktasi tertentu dan tidak memperlihatkan pola gerakan yang dapat diamati. Dengan Reynold Number diatas 3 x $10^{6}$. Aliran transisi adalah batas perubahan antara aliran laminar menuju aliran turbulen Reynold Number berada diantara $10^{5}$ dan $3 \times 10^{6}$.

\subsection{Drag Coefficient}

Merupakan suatu nilai yang menunjukan koefisien tahanan dari sebuah obyek benda terhadap fluida. Semakin streamline bentuk benda maka koefisien hambat udara yang dihasilkan semakin kecil, dan semakin besar penampang benda maka semakin besar koefisien hambat udara yang dihasilkan.

$$
\begin{aligned}
& \mathrm{CD}=\frac{\mathrm{FD}}{\frac{1}{2} \rho \mathrm{V}^{2} \mathrm{~A}} \text { (Frank M. White, 1975:28 } \\
& \text { Dimana: } \\
& \mathrm{CD}=\text { Koefisien Hambat } \\
& \rho=\text { Densitas udara }\left(\mathrm{kg} / \mathrm{m}^{3}\right) \\
& \mathrm{V} \quad=\text { Kecepatan relative benda } \\
& \text { terhadap udara }(\mathrm{m} / \mathrm{s}) \\
& \text { A } \quad=\text { Luas penampang }\left(\mathrm{m}^{2}\right) \\
& \text { FD = Gaya hambat }(\mathrm{N})
\end{aligned}
$$

Pengaruh bentuk benda terhadap koefisien hambat pada benda tumpul seperti bola, kotak akan lebih besar jika dibandingkan dengan benda streamline seperti airfoil, benda runcing. Jika terjadi suatu aliran diatas permukaan yang searah dengan panjangnya dibandingkan tingginya maka benda tersebut disebut dengan streamline. Hal ini karena benda yang streamline maupun benda runcing mempunyai daerah wake (olakan aliran dibelakang benda) yang lebih kecil dibandingkan dengan benda tumpul.

\subsection{CFD}

CFD (Computational Fluid Dynamic) adalah metode perhitungan dengan sebuah kontrol dimensi, luas dan volume dengan memanfaatkan bantuan komputasi komputer untuk melakukan perhitungan pada tiap-tiap elemen pembaginya. Prinsipnya adalah ruang yang berisi fluida yang akan dilakukan perhitungan dibagi-bagi menjadi beberapa bagian, hal ini sering disebut dengan sel dan prosesnya dinamakan meshing.

Dalam menyelesaikan proses analisis menggunakan fluent, maka diperlukan suatu perencanaan analisis CFD (Computational Fluid Dynamic), yang terdiri dari menentukan tujuan pemodelan, pemilihan model komputasional, pemilihan model fisik dan penentuan prosedur

Secara umum proses penghitungan CFD terdiri atas 3 bagian utama:

\section{Pre-processor}

Pre-processor adalah tahap dimana data di input mulai dari pendefinisian domain serta pendefinisian kondisi batas atau boundary condition. Ditahap ini juga sebuah benda atau ruangan yang akan dianalisa dibagi - bagi dengan jumlah 
grid tertentu atau sering juga disebut dengan meshing.

2. Processor

Padatahap ini dilakukan proses penghitungan data - data input dengan persamaan yang terlibat secara iteratif. Artinya, penghitungan dilakukan hingga hasil menuju error terkecil atau hingga mencapai nilai yang konvergen Penghitungan dilakukan secara menyeluruh terhadap volume kontrol dengan proses integrasi persamaan diskrit.

3. Post processor

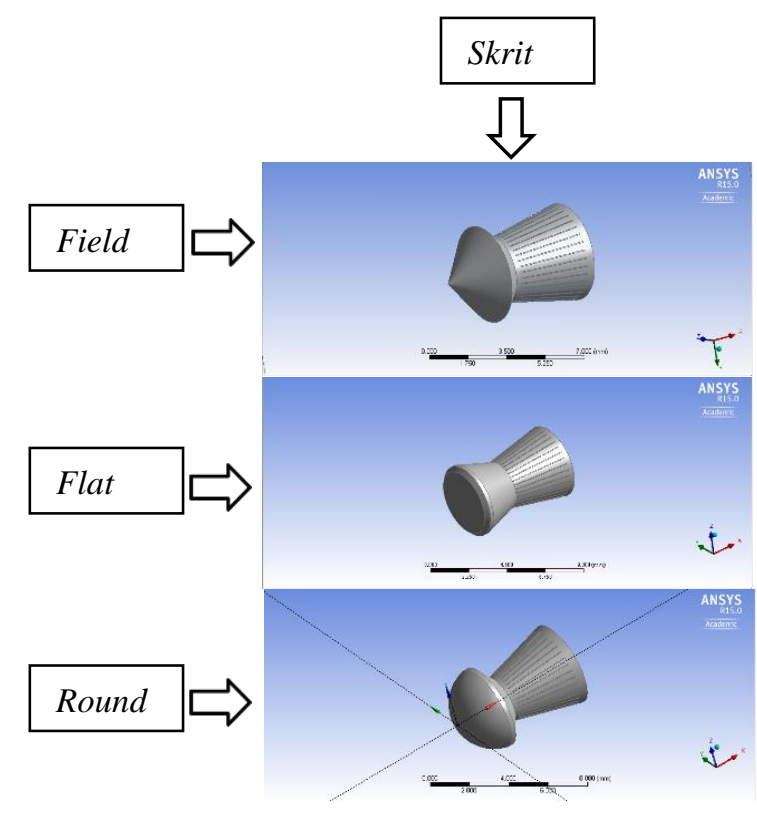

Hasil perhitungan diinterpretasikan ke dalam gambar, grafik bahkan animasi dengan pola tertentu.

\section{METODE PENILITIAN}

Prosedur yang dilakukan dalam penelitian ditunjukkan oleh digram alir penelitian gambar 3.1.

\subsection{Desain Geometri Peluru}

Pada tahap ini dilakukan desain geometri terhadap peluru yang akan diteliti. Ada 3 desain geometri kepala peluru yaitu field point, flat nosed dan round head dengan variasi bentuk badan skirt dan lurus.

Gambar 3.1 Desain Geometri Peluru

\subsection{Tahap Simulasi}

Tahap selanjutnya adalah menyelesaikan proses analisis menggunakan fluent, maka diperlukan suatu perencanaan analisis CFD (Computational Fluid Dynamic), yang terdiri dari menentukan tujuan pemodelan, pemilihan model komputasional, pemilihan model fisik dan penentuan prosedur. Langkah - langkah umum penyelesaian analisis CFD pada fluent dapat digambarkan sebagai berikut:

1. Membuat geometri dan mesh pada model

2. Memilih solver yang tepat untuk model tersebut
3. Mengimpor mesh model

4. Melakukan pemeriksaan pada mesh model

5. Melakukan formulasi solver

6. Memilih persamaan dasar yang akan dipakai dalam analisis

7. Menentukan sifat material yang akan digunakan

8. Menentukan kondisi batas

9. Mengatur permukaan kontrol solusi

10. Initialize the flow field

11. Melakukan perhitungan / iterasi

12. Memeriksa hasil perhitungan

13. Menyimpan hasil perhitungan 


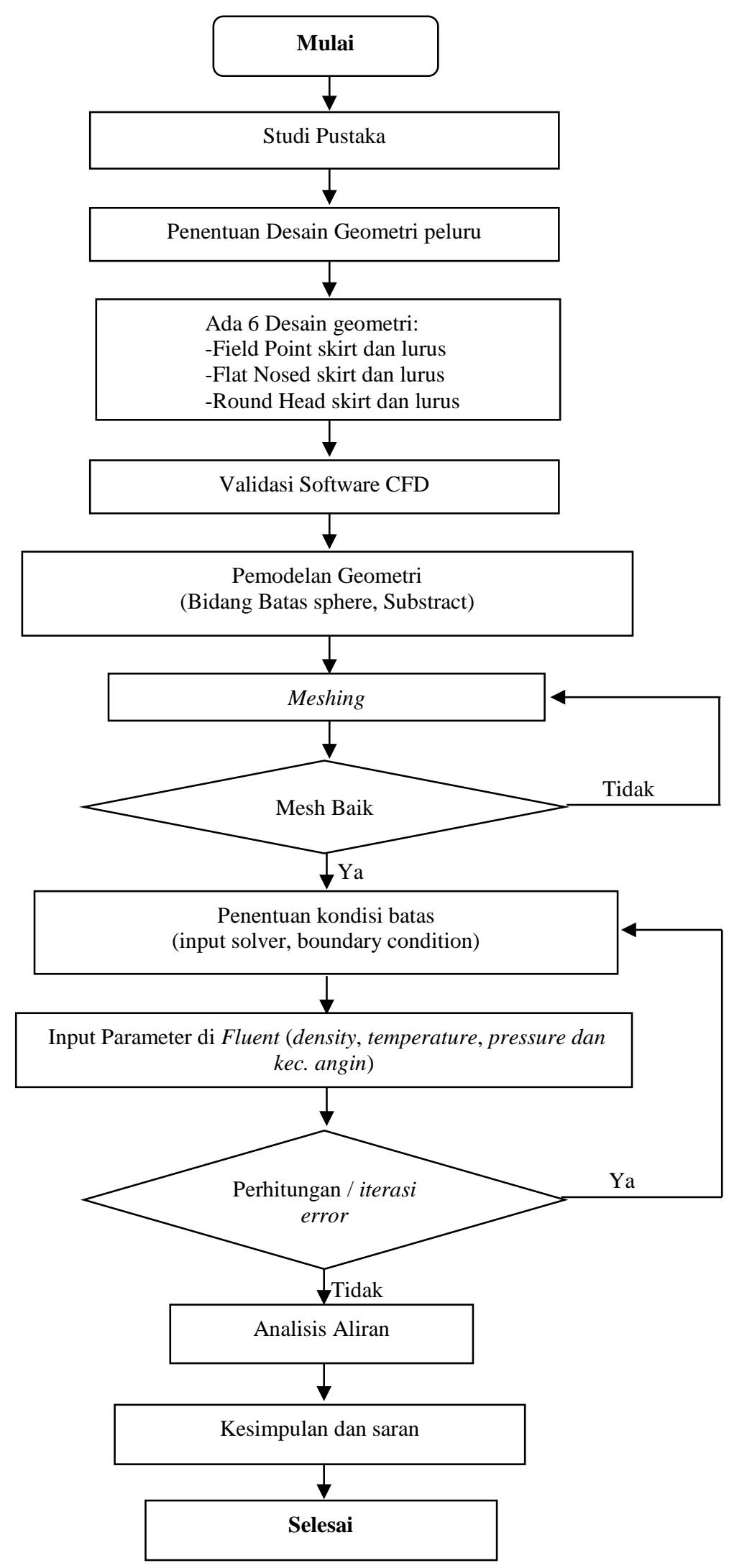

Gambar 3.2 Diagram alir penelitian 


\section{HASIL DAN PEMBAHASAN 4.1 Coefficient Drag}

Pada simulasi yang dilakukan terhadap 3 bentuk peluru dengan masing-masing memiliki 2 model berbeda dengan kecepatan $1000 \mathrm{ft} / \mathrm{s}$ atau $304,8 \mathrm{~m} / \mathrm{s}$, maka didapat hasil nilai coefficient drag sebagai berikut:

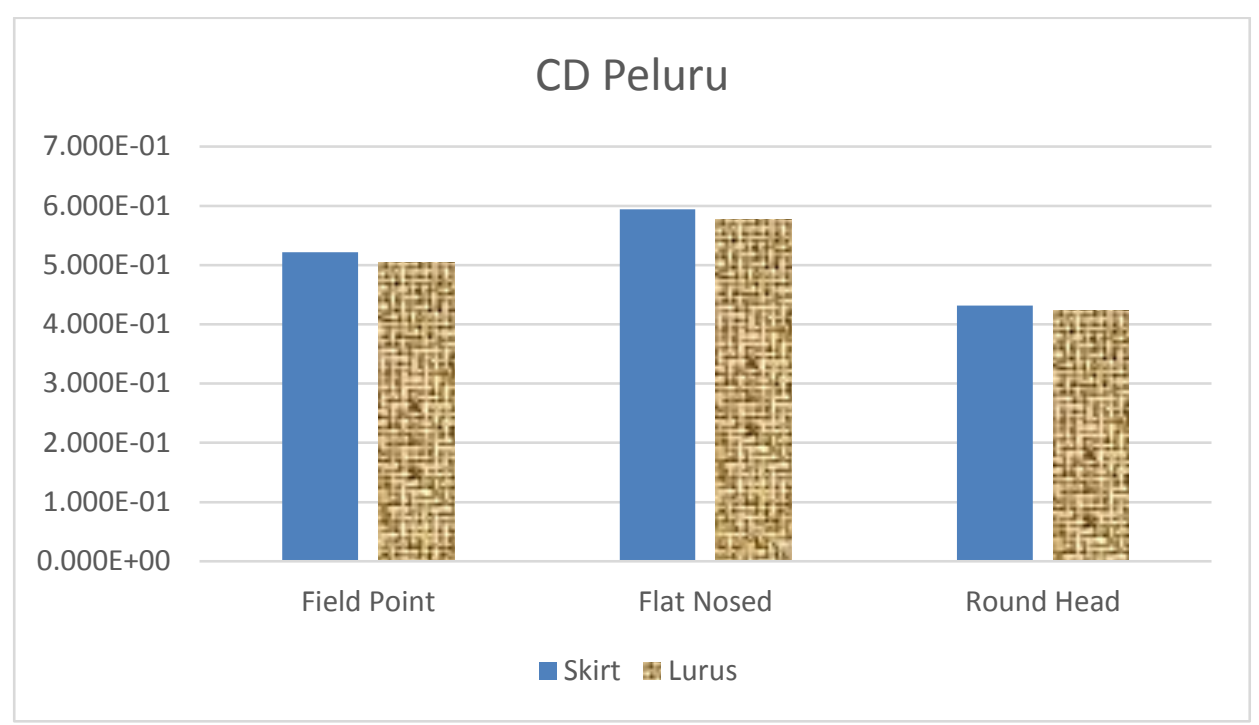

Gambar 4.1 Grafik Nilai CD Peluru

Tabel 4.1 Nilai CD Peluru

\begin{tabular}{|c|c|c|}
\hline \multirow{2}{*}{ Peluru } & Model & Coefficient Drag \\
\hline \multirow{3}{*}{ Field Point } & Field Point Skirt & 0,5219 \\
\cline { 2 - 3 } & Field Point Lurus & 0,5045 \\
\hline \multirow{2}{*}{ Flat Nosed } & Flat Nosed Skirt & 0,5943 \\
\cline { 2 - 3 } & Flat Nosed Lurus & 0,5773 \\
\hline \multirow{2}{*}{ Round Head } & Round Head Skirt & 0,4313 \\
\cline { 2 - 3 } & Round Head Lurus & 0,4232 \\
\hline
\end{tabular}

Dari tabel 4.1 dapat disimpulkan bahwa drag coefficient terhadap bentuk peluru masingmasing berbeda namun pada setiap variasinya tidak terjadi perbedaan Drag Coefficient yang besar. Jenis peluru dengan variasi bentuk badan skirt cenderung memiliki nilai Drag Coefficient yang lebih besar dibandingkan dengan peluru dengan bentuk badan lurus. Drag coefficient terbesar dialami oleh bentuk peluru flat nosed skirt dengan nilai drag coefficient 0,5943. Sementara nilai drag coefficient terendah dialami oleh bentuk peluru round head lurus dengan nilai drag coefficient 0,4232 . 


\subsection{Kontur Tekanan}
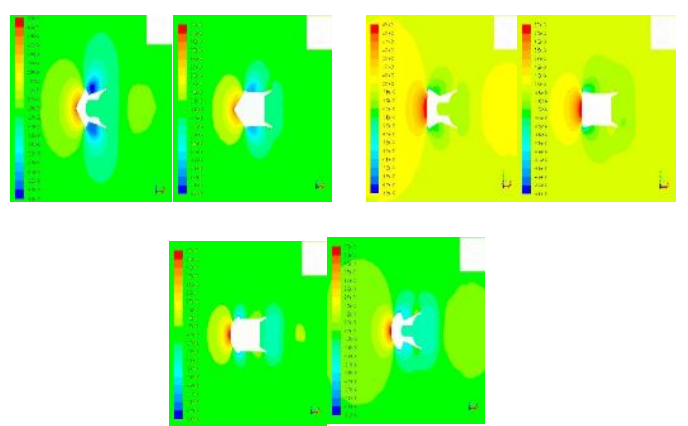

Gambar 4.2 Perbandingan Kontur Tekanan Peluru

Terlihat dari gambar 4.2 peluru jenis flat nosed mempunyai tekanan yang lebih besar dibandingkan jenis peluru yang lain, dikarenakan bentuk kepala peluru yang tidak streamline membuat tekanan pada kepala peluru jenis ini memiliki tekanan yang paling besar. Oleh karna perbedaan tekanan ini lah yang membuat nilai drag coefficient dari peluru ini lebih besar dari jenis yang lainnya.

\subsection{Kontur Velocity}

\subsubsection{Kontur Velocity Field Point}
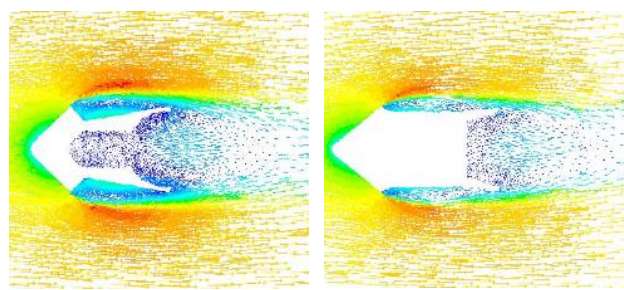

Gambar 4.3 Perbandingan Kontur Velocity Field Point Skirt (kiri) Lurus (kanan)

Dari gambar 4.3 terlihat peluru field point skirt memiliki daerah separasi aliran yang lebih luas menyelimuti badan peluru dibandingkan dengan field ponint lurus. Hasil simulasi peluru field point skirt memiliki nilai koefisien hambat sedikit lebih tinggi dibandingkan dengan variasi lurus (non-skirt) hal ini disebabkan semakin kecil daerah separasi aliran maka semakin kecil pula koefisien tahanannya.

\subsubsection{Kontur Velocity Flat Nosed}

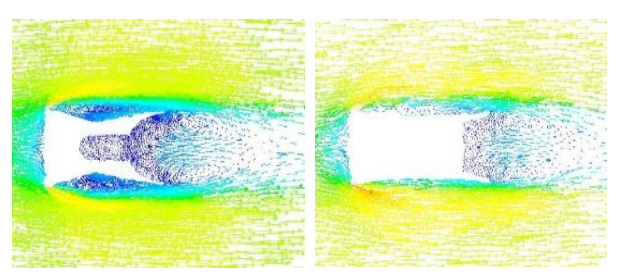

Gambar 4.4 Perbandingan Kontur Velocity Flat Nosed Skirt (kiri) Lurus (kanan)

Dari gambar 4.4 terlihat peluru flat nosed skirt memiliki daerah separasi aliran yang lebih luas menyelimuti badan peluru dibandingkan dengan flat nosed lurus. Hasil simulasi peluru flat nosed skirt memiliki nilai koefisien hambat sedikit lebih tinggi dibandingkan dengan variasi lurus (non-skirt) hal ini disebabkan semakin kecil daerah separasi aliran maka semakin kecil pula koefisien tahanannya.

\subsubsection{Kontur Velocity Round Head}
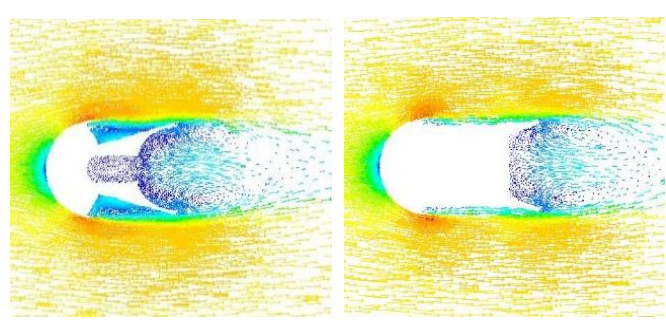

Gambar 4.5 Perbandingan Kontur Velocity Round Head Skirt (kiri) Lurus (kanan)

Dari gambar 4.5 terlihat peluru round head skirt memiliki daerah separasi aliran yang lebih luas menyelimuti badan peluru dibandingkan dengan round head lurus. Hasil simulasi peluru round head skirt memiliki nilai koefisien hambat sedikit lebih tinggi dibandingkan dengan variasi lurus (non-skirt) hal ini disebabkan semakin kecil daerah separasi aliran maka semakin kecil pula koefisien tahanannya 


\subsubsection{Perbandingan Kontur Velocity Peluru}

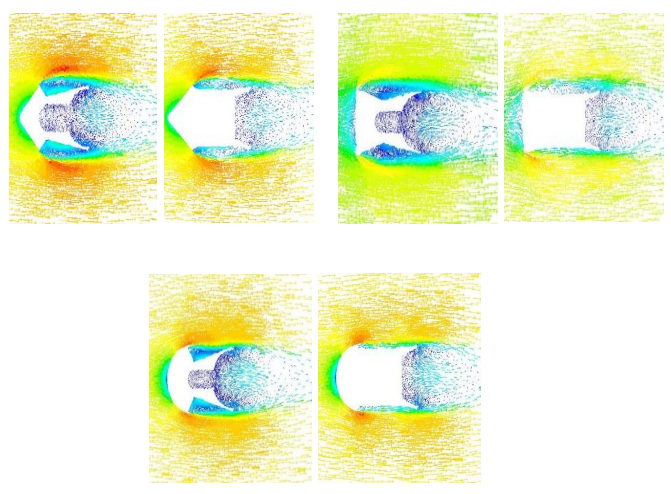

Gambar 4.6 Perbandingan Kontur Velocity Peluru

Terlihat dari gambar 4.6 perbandingan vector velocity dari setiap jenis peluru, peluru dengan jenis skirt memiliki daerah separasi yang lebih luas dibandingkan dengan jenis variasi lurus. Selaras dengan hasil simulasi peluru dengan jenis skirt dari setiap jenis kepala peluru memiliki nilai drag coefficient yang lebih tinggi dibandingkan dengan jenis lurus. Namun, dengan adanya variasi skirt dalam bentuk badan peluru memungkinkan jenis peluru skirt lebih stabil dibandingkan jenis peluru lurus dikarenakan gaya drag dan gaya angkat negatif. yang membuat gerak peluru menjadi lebih stabil.

\subsection{Hasil Kontur Pathline Velocity}

4.4.1 Perbandingan Pathline Velocity Field Point

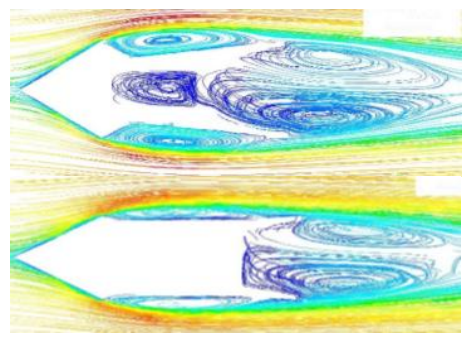

Gambar 4.7 Perbandingan Pathline Velocity Field Point

Pada gambar 4.7 memperlihatkan perbandingan pathline pada peluru jenis field point, terlihat aliran pada peluru filed point lurus lebih teratur yang menyebabkan nilai drag coefficient pada jenis peluru tersebut lebih rendah dibandingkan pada peluru field point skirt. Namun, gerakan peluru field point skirt cenderung lebih stabil dikarenakan daerah olakan pada peluru tersebut lebih luas.

\subsubsection{Perbandingan Pathline Velocity Flat}

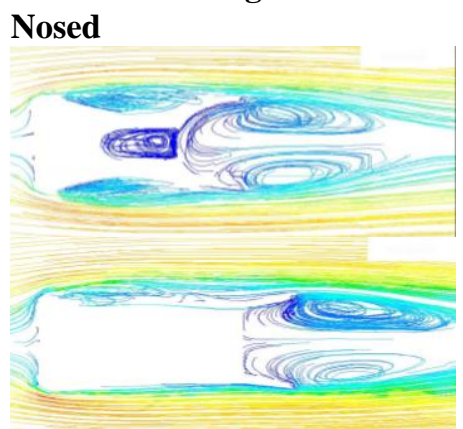

Gambar 4.8 Perbandingan Pathline Velocity Flat Nosed

Pada gambar 4.8 memperlihatkan perbandingan pathline pada peluru jenis flat nosed, terlihat aliran pada peluru flat nosed lurus lebih teratur yang menyebabkan nilai drag coefficient pada jenis peluru tersebut lebih rendah dibandingkan pada peluru flat nosed skirt. Banyaknya olakan yang terjadi pada peluru flat nosed skirt menyebabkan peluru jenis ini memiliki drag coefficient yang lebih tinggi dibandingkan jenis peluru yang lainnya. Namun, dengan banyaknya olakan yang terjadi membuat peluru jenis flat nosed skirt lebih stabil dibandikan dengan peluru lainnya

\subsubsection{Perbandingan Pathline Velocity Round Head}

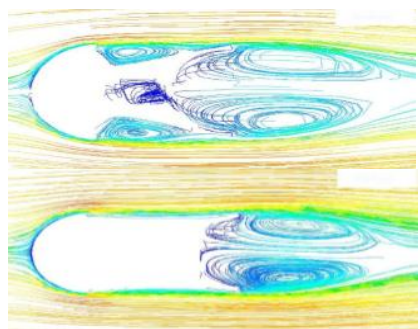

Gambar 4.9 Perbandingan Pathline Velocity Round Head

Pada gambar 4.9 memperlihatkan perbandingan pathline pada peluru jenis round head, terlihat aliran pada peluru round head lurus lebih teratur yang menyebabkan 
nilai drag coefficient pada jenis peluru tersebut lebih rendah dibandingkan pada peluru flat nosed skirt. Sedikitnya olakan yang terjadi pada peluru round head lurus dan bentuk peluru yang lebih aerodinamis menyebabkan peluru jenis ini memiliki drag coefficient yang paling rendah dibandingkan jenis peluru yang lainnya. Namun, jenis peluru ini cenderung lebih tidak stabil

\subsubsection{Perbandingan Kontur Pathline Velocity Peluru}

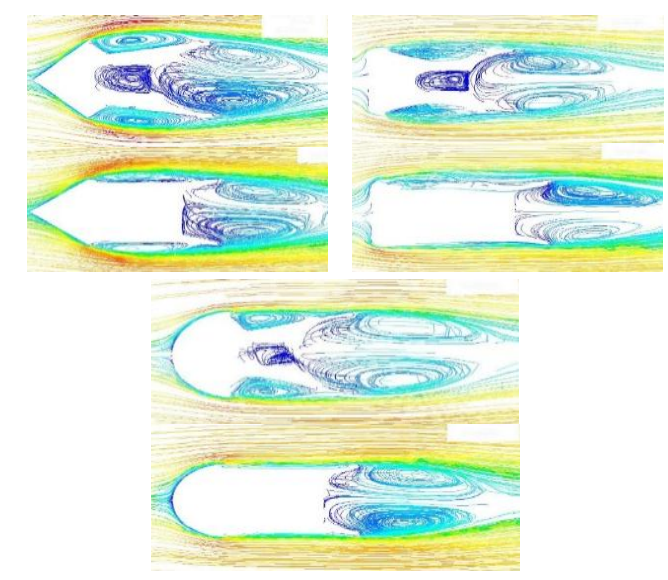

Gambar 4.10 Perbandingan Kontur Pathline Velocity Peluru

Dilihat dari gambar 4.10 bentuk aliran yang paling teratur adalah peluru round head lurus sedangkan aliran yang paling banyak memiliki olakan adalah peluru jenis flat nosed skirt. Namun dari gambar diatas juga bisa dilihat bahwa peluru round head lurus kurang stabil dibanding peluru lainnya sedangkan peluru flat nosed skirt cenderung memiliki tingkat kestabilan dibanding peluru lainnya.

\section{KESIMPULAN dan SARAN}

Berdasarkan penelitian yang telah dilakukan terhadap ke enam peluru senapan angin, maka didapat saran dan kesimpulannya sebagai berikut:

\subsection{Kesimpulan}

Dari simulasi yang telah dilakukan terhadap ke enam peluru senapan angin dimana 3 bentuk kepala peluru field point, flat nosed, dan round head serta variasi pada setiap jenis kepalanya skirt dan lurus (non-skirt) pada kepacatan 304,8 m/s atau sama dengan 1000 $\mathrm{ft} / \mathrm{s}$, maka dapat diambil beberapa kesimpulan:

1. Peluru yang mempunyai drag coefficient terendah adalah model round head lurus. Hal ini dapat dilihat dari nilai drag coefficient sebesar 0,4232. Nilai drag coefficient tertinggi adalah model flat nosed skirt. Hal ini dapat dilihat dari nilai drag coefficient sebesar 0,5943 .

2. Tekanan udara terbesar selalu terjadi pada bagian depan kepala peluru sedangkan tekanan udara rendah ada dibagian badan dan belakang peluru.

3. Jenis peluru lurus mempunyai bentuk aliran lebih teratur dibandingkan dengan jenis skirt. Jenis peluru skirt cenderung lebih stabil dibandingkan jenis lurus dikarenakan gaya drag dan gaya angkat negatif yang terjadi pada peluru dengan jenis skirt sedikit lebih banyak dibandikan dengan peluru dengan jenis lurus.

\subsection{Saran}

Setelah melakukan penelitian terhadap peluru senapan angin maka untuk kebaikan penelitian selanjutnya yang berhubungan dengan aerodinamika, maka peneliti memberikan saran sebagai berikut.

1. Sebaiknya untuk penelitian selanjutnya percobaan dilakukan tidak hanya melalui metode computational saja tetapi sebagai acuannya maka penelitian juga dilakukan dengan menggunakan metode eksperimen

2. Sebaiknya percobaan untuk mengurangi nilai drag coefficient pada peluru senapan angin tidak hanya berfokus pada variasi bagian badan saja, tetapi dibagian lain pada bagian kepala peluru.

3. Sebaiknya untuk penilitian selanjutnya percobaan dilakukan tidak hanya pada 3 bentuk kepala peluru, tetapi dilakukan pada jenis kepala peluru yang lainnya dan dalam bentuk variasi badan yang berbeda.

4. Sebaiknya untuk penelitian selanjutnya percobaan tidak hanya mencari nilai drag coefficient tetapi juga mencari nilai lift coefficient. 


\section{DAFTAR PUSTAKA}

Agarwal, P.K. 2011. IIT Physics. India: Krishna Prakashan Media. Apoorv, Shelke dkk, The Bullet. Budiarto, Hairil. Progresi Geometri Untuk Perbaikan Kinerja Traksi Pada Mesin Kendaraan. 2013. Madura: Fakultas Teknik Universitas Trumojoyo Madura Cengel, Y. 2006. Fluid Mechanics. New York: Mc Graw Hill

Clancy, L. J. 1975. Aerodynamics. London: Pitman Publishing Limited

Gerhart, Philip M dkk. 1985. Fundamentals of Fluid Mechanics. USA: Addison

Wesley Publishing Company

Hyne, Norman J. 2012. Petroleum Geogoly, Exploration, Drilling \& Production.

Okhlahoma, PennWell

Johnson, Richard W., 2000. Fluid Dynamics. USA: CRC Press LLC

Kundu, Pijush K. 2002. Fluid Mecanics. USA: Academic Press

McCormick, Barnes W. 1979. Aerodynamics, Aeronautics, and Flight Mechanics.

New York: John Wiley \& Sons

McCoy, Robert L. 1988. The Aerodinamic Characteristics of 7.62MM Match
Bullets. USA: Ballistic Research Laboratory

McGinnis, Peter M. 2013. Biomechanics of Sport and Exercise. New York:

Human Kinetics

Satrijo, Djoeli. 1999. Dinamika Kendaraan Modul I. Semarang. Fakultas Teknik

Univesitas Diponegoro

Stewart, James. 2012. Multivariable Calculus. USA: Brooks

Tantowi, Alva Edy. 1989. Laporan Penelitian. Menentukan Matra Spoiler pada

Kendaraan Minibus untuk Mempertinggi Traksi.Yogyakarta Universitas Gadjah Mada

Wulandari, Betty. 2010. Pengaruh Koefisien Hambatan Udara Pada Bentuk Lokomotif Terhadap Gaya Aerodinamis Kereta Api Argo Lawu. Surakarta:

Fakultas Keguruan dan Ilmu Pendidikan Universitas Sebelas Maret

Middleton, Richard. 2005. The Practical Guide to Man-Powered Bullets: Catapults, Crossbows, Blowguns, Bullet-Bows and Airguns. USA: Stackpole Books

BASC. 2016. Air Riffle Safety in England and Wales: A Code of Practice. Marford Mill, Rossett 